\title{
Correction to: A systematic review and meta-analysis of couple-based intervention on sexuality and the quality of life of cancer patients and their partners
}

\author{
Minjie $\mathrm{Li}^{1} \cdot$ Carmen W. H. Chan ${ }^{1} \cdot \mathrm{Ka} \mathrm{Ming} \mathrm{Chow}^{1} \cdot$ Jinnan Xiao ${ }^{1} \cdot$ Kai Chow Choi $^{1}$ \\ Published online: 26 May 2020 \\ (C) Springer-Verlag GmbH Germany, part of Springer Nature 2020
}

\section{Correction to: Supportive Care in Cancer} https://doi.org/10.1007/s00520-019-05215-z

The original version of this article unfortunately contained an error. The sentence:

Jonsdottir et al. [18] reviewed sexuality from the neotheoretical framework of sexuality interventions delivered on the internet but focused on synthesizing the characteristics of couple-based intervention studies and recognizing how such interventions are best structured, paying limited attention to outcome evaluation.

Should read:

Jonsdottir et al. [18] reviewed sexuality from the neotheoretical framework of sexuality interventions delivered by face-to-face, telephone, videoconference, group format or internet.

Publisher's note Springer Nature remains neutral with regard to jurisdictional claims in published maps and institutional affiliations.

The online version of the original article can be found at https://doi.org/ $10.1007 / \mathrm{s} 00520-019-05215-\mathrm{z}$

Carmen W. H. Chan

whchan@cuhk.edu.hk

1 The Nethersole School of Nursing, The Chinese University of HongKong, Shatin, Hong Kong 